Birlesik Dünya Arastırma

BD-CENTER

Innovasyon ve Yayıneılık Merkezi

\section{Global Journal of \\ Arts Education}

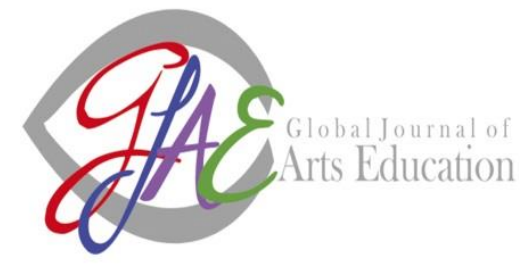

www.gjae.eu

Volume 11, Issue 1, (2021) 01-12

\title{
Critical design method as an approach to improve design thinking among Pearl Academy students
}

\author{
Manju Sugathana ${ }^{a}{ }^{*}$, Academic Governance Officer, Pearl Academy, Mumbai, India
}

\section{Suggested Citation:}

Sugathana, M. (2021). Critical design method as an approach to improve design thinking among Pearl Academy students. Global Journal of Arts Education. 11(1), 01-12. https://doi.org/10.18844/gjae.v11i1.5458

Received from October 10, 2020; revised from December 28, 2020; accepted from February 10, 2021.

Selection and peer review under responsibility of Prof. Dr. Ayse Cakir Ilhan, Ankara University, Turkey.

${ }^{{ }^{2}} 2021$ Birlesik Dunya Yenilik Arastirma ve Yayincilik Merkezi. All rights reserved.

\section{Abstract}

Over the course of time designers have mastered the skill that can be applied to resolve a wide range of problems through analysis of a hypothesis using different research methods strategically and iterativelyCritical design thinking could be applied as an approach to favour the designers to focus on future requirements of people and see beyond their ideological constrains in design. The purpose of the study is to test: by employing critical design method in design education to help the students learn, analyse and evaluate ideas and concepts in a critical manner. Also, it examines critical design as a method for questioning and improving design thinking among students that synergises perfectly with future design thinkers as well as their potential audience. A critical design workshop is conducted in Pearl Academy, Mumbai by the author to test and develop this way of thinking among design students. The workshop results are analysed under Bloom's taxonomy, which is a set of three hierarchical models used to classify educational learning objectives under analysis, synthesis and evaluation. An advantage of critical design, is that the method allows students to temporarily move away from problem solving, focusing on asking questions instead of providing answers.

Keywords: First keyword, second keyword, third keyword, forth keyword;

* ADDRESS FOR CORRESPONDENCE: Manju Sugathana, Academic Governance Officer, Pearl Academy, Mumbai, India

E-mail address: manju.sugathan@gmail.com 


\section{Introduction}

Critical design is a term built on the 1970's Italian radical design approaches and it is first discussed by Dunne in 1997 in his book 'Hertzian tales'. He rejects how current situations are assumed as the only possibility and provides a critique of the prevailing situation through designs that embody alternative social, cultural, technical, or economic values (Dune and Raby, 2001). The focus of critical design is to make people think and thus raise awareness and develop a debate to provoke positive action. Critical design has been used over the years to examine social, political, economic, and environmental issues in society (Dunne \& Raby, 2001; Torkildsby, 2018).

Antony Dunne and Fiona Raby's Design Interaction MA course at the Royal college of Art practice speculative and critical design ( $S C D$ ) as a way of challenging the students to defy norms and work to critically and reflectively through projects. This project predominantly occurs in studios and classrooms, where students are free from client constraints and expectations. The purpose of critical education in design is to carry the principals learned by the student will impact the way they work with clients and partners creating a more critical field in future. Dunne and Raby (2001) describe critical design, which permits design practitioners and audience to challenge narrow assumptions and preconceptions about the role of products play in everyday life. Critical approach to visual and material culture, in the form of critical design has a role in challenging future by seeing the means of their aesthetics, by creating an intuitive relationship with the audience that builds on their own lived experience (Ravell \& Voss, 2018).

Critical design is a "research strategy dedicated to transgressing and undermining social conformity, passivity, and similar values of capitalist ideology, in hopes of bringing about social emancipation" (Bardzell \& Bardzell,2013, p:3302; Verganti, 2008). Spence et.al (2015) argue that liminality, which aims to place its users in a position of questioning their relationship to a design and the socio-cultural systems underlying it can be a key concept for critical design. According to Jackobsone (2017, p: 4256) "engage designers in a different kind of thinking that delivers more conscious design products", and, furthermore, focuses on "presenting social, cultural and ethical implications of design objects and practice" (Malpass, 2017). In this respect, critical design as a method of sparking reflection, discussion, engagement, compassion, and ultimately innovation - even if this originates on the 'dark side' of design thinking (Torkildsby, 2018).

Critical Design moves away from traditional approaches that limit design's role to the production of profitable objects, focusing instead on a practice that is interrogative, discursive, and experimental (Malpass, 2017). Three types of critical design practice termed by Malpass (2017) are associative design, speculative design, and critical design. The aim of associative design approach is to present means for both designers and users to rethink dominant traditions and values in designed objects and their environment. The critical design's intention is to engage the audiences' imagination and intellect to convey a message and it often depicts fictive scenarios. Finally, speculative design developed from critical design focus on science and technology establishing and projecting scenarios of use which makes visible what is emerging, by both slowing down the present and speeding us up to that present's future (Bhar, 2019).

Critical design is ambiguous in nature and has been subject to increasing debate in design (Jain, 2018). Critical design favours the development of critical thinking that supports the personal understanding of a design idea or proposal through expanding the meaning of design thinking. It can be adapted as a method challenging and improving the field of design, in order to achieve best teaching 
and learning in universities and design colleges (Özdemir, 2020). In this study author is considering its capability to engage design student in questioning and improving their design thinking that delivers more conscious design; also encourage them to consider the 'dark side of design' in their design thinking. This will help them to design for a larger diverse population through personal understanding of their needs and wants. The aim of the study is to test by employing critical design method in design education to help the students learn, analyse, and evaluate ideas and concepts in a critical manner. Also, it examines critical design as a method for questioning and improving design thinking among students that synergises perfectly with future design thinkers as well as their potential audience.

\subsection{Critical Design and its implications, scope, and limitation in design education}

"Critical design uses design to explore alternative views of the world, to materialise questions and to engage the audience into a reflective state. But its generalisation suffers from a lack of sharable methodology" (Gentes \& Mollon, 2015, p: 79). They observe that critical design practices play on emotions to incite interest, concerns and reflection. The artefacts have a narrative strategy depending on the uncanniness, allowing curiosity, concern and avoiding visceral reactions of rejection. Its expression is based on the originality of work and the structure of arguments to support and counterbalance the uncanniness of narration (Fued, 2004, Gentes \& Mollon, 2015).

For a broader uptake on critical design, the literature is underdeveloped to offer the practical support needed to understand the concept. The design researchers and theorists have to decode the theories of critical design in ways that we as a community want to see it used. In this case we have to look beyond Dune and Raby to understand the term critical that is found in their writings and iterating on present understanding of critical design with a broader view of critical thinking. This is not to offer a pure notion of critical design, but to provide a wider and acceptable range of conceptual ideas that design researchers can use in their work (Bardzell \& Bradzell, 2013).

In this context the author conducted a workshop on critical design (CD) in Pearl Academy (PA) Mumbai for design students. The workshop started with explaining the critical design concept to the participants, followed by discussion on designs develop under CD. One example of Dune and Raby's critical design chosen for a debate in the workshop is 'teddy bear blood bank radio'. The workshop participants found the idea bit 'creepy'. They did not like the concept of a pet losing its life to keep you feel better. The debate went interesting when a participant comment that "her pet bleeds to keep her feel better and still love her; would definitely develop an emotional attachment to it".

The question is how critical design overturn the system, engage the user's imagination, and bring social change. According to Bardzell \& Bradzell (2013), Dune describes critical design as a form of social research, so the primary intended outcome is knowledge and not to design a product; the purpose is to seduce the viewer into the world of ideas rather than objects.

\section{Methodology}

\subsection{Applying Critical design method through a workshop}

The six stages of Bloom's taxonomy can be used as a functional assessment tool to measure students' learning and critical thinking skills. Bloom's taxonomy is composed of six steps in total: three steps in low order and three steps in high order cognitive skills (Eber \& Parker, 2007). However, considering the changes in the society over the decades, the revised Bloom's taxonomy provides a 
powerful tool to fit the present teaching requirements. The revised taxonomy table matrix provides a clear concise representation of alignment of standards, educational goals, objectives, and activities (Krathwohl, 2002).

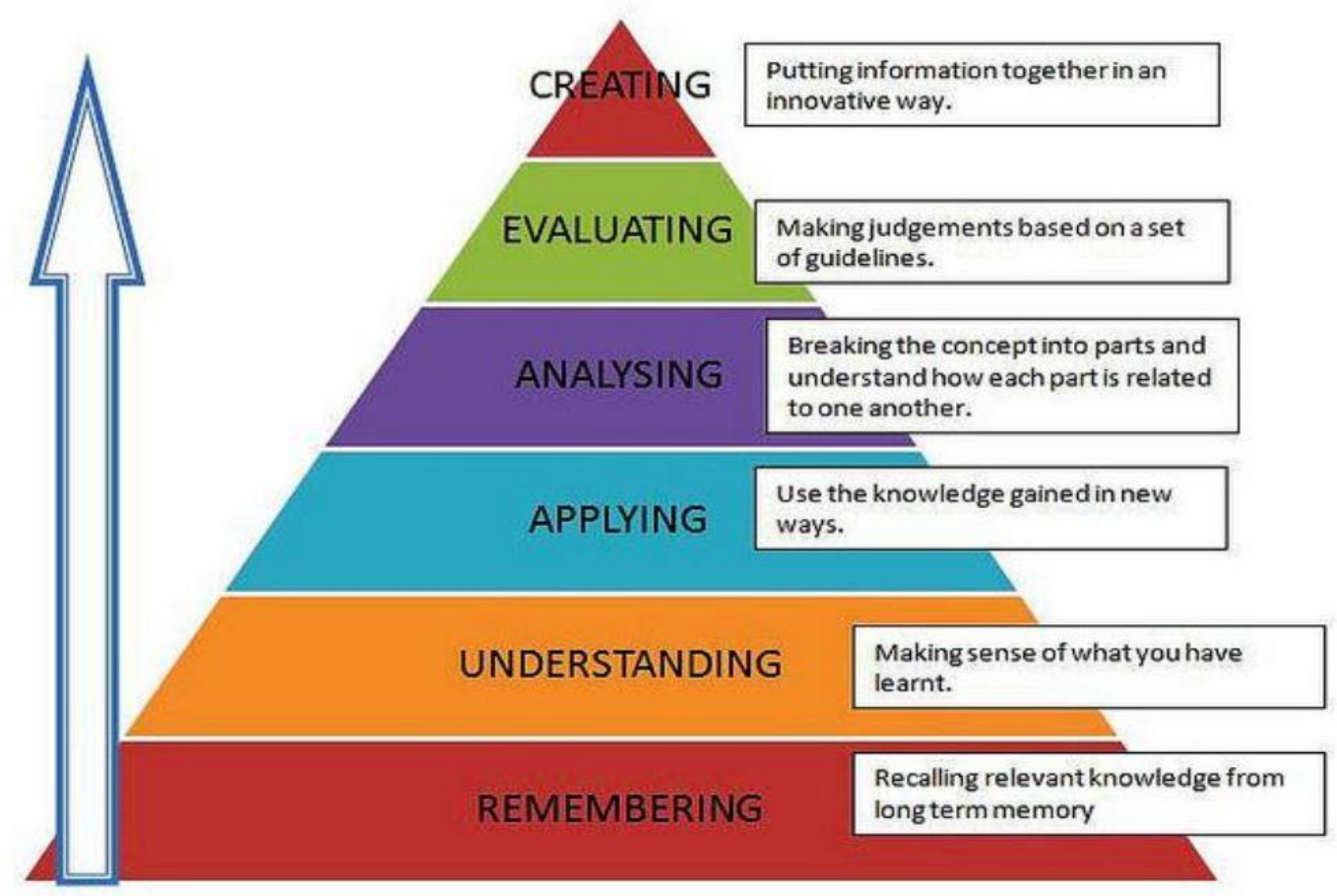

Fig: 1 Bloom's taxonomy of educational objectives Robyn (2014)

The terms are defined as:

- $\quad$ "Remembering: retrieving, recognising, and recalling relevant knowledge from long term memory

- Understanding: constructive meaning from oral, written, and graphic messages through interpreting, exemplifying, classifying, summarising, inferring, comparing, and explaining

- Applying: carrying out or using a procedure through executing or implementing

- Analysing: breaking material into constituent parts, determining how the parts relate to one another and to an overall structure or purpose through differentiating, organising, and attributing

- $\quad$ Evaluating: making judgements based on criteria and standards through checking ad critiquing

- $\quad$ Creating: putting elements together to form a coherent or functional whole; recognising elements into a new pattern or structure through generating, planning, or producing" (Andreson \& Krathwohl, 2001, p: 68)

Bloom's Taxonomy addresses the arrangement of learning aims in the education process that educators appoint for learners. The cognitive domain within Bloom's taxonomy, which is set to confirm a student's cognitive level (Haris \& Omar, 2015) is the core of classifying statements according to what is expected from students to learn at the end of the instructional activities (Krathwohl, 2002). 
This makes the instructors to be more conscious of the content and the process, they teach and assess, as well as indicating disparities between what is taught and what is assessed. Moreover, "it can perform as a guide to evolve and expand the learning and assessment activities by supplying a concrete consciousness of the content and process- an instructor defines as essential in the development of learners' cognition" (Kastberg, 2003, p. 405).

In order to test the concept of Critical design, a workshop with design students in Pearl Academy, Mumbai is conducted by the author. The focus of the workshop is to provide the participants a firsthand experience of the dark side of design thinking.

The objectives for the workshop are

- The workshop participants design process will be termed as critical design examples

- The design brief for the workshop is to illuminate a problem and the participants are intended to be applied to the problem-solving process to foster innovation

- The idea of the workshop is to force the participants out of their comfort zone, think outside the box and find a solution for the design problem

The length of the workshop was 5 hours, the order and structure of the workshop is as follows:

- Brief student introduction and over view of the workshop

- Introduction to critical design and a brief run through with examples of critical design followed by discussions for inspiration

- A demonstration of application of critical thinking in critical design

- Presentation of designs with students divided into groups in the workshop

- Followed by discussion and summing of the workshop

The workshop was attended by18 participants from under graduation and post-graduate diploma courses in Pearl Academy, Mumbai. The participants were design students from different disciplinarians, product design, communication design, interior architecture design and fashion styling. As the field of design research matured, the need for collaboration between researchers with common interest in different disciplinary practices emerged in 1994. Sharing of empirical data supporting their research leads to interesting research findings through triangulation of findings conspiring to better understanding of design thinking and the resultant knowledge that emerge from it (McDonell and Lloyd, 2014; Fitsumbirhan, Kelkay \& Asrat, 2020).

A consent form was signed by all participants before the end of the workshop that clearly states that the students were able to withdraw their consent at any time. Also explaining the quotations, pictures and sketches produced in the workshop would be used for the project report and related publications. The author played an active role in conducting the workshop, whereas in the role of a teacher providing necessary direction and guidance, also an active observer.

\subsection{Workshop procedure}

Students were encouraged to discuss on traditional design thinking, radical design, and design for future before commencing their task of designing using critical design method. Participants were challenged to identify problem from an exciting design, which seems to be a fully resolved. Participants were put in three groups of six each. Each group was given a scenario to design, cinema halls in Mumbai, Mumbai metro and Mumbai Pearl Academy canteen. From these three concepts participants explored the idea of movie ticketing in cinema halls (Group A), chips dispenser in the collage canteen (Group B) and passenger holding bars in Mumbai metro trains (Group C). 
The design process of all groups should "reject the idea of something that is affirmative rather than critical and explanatory rather than affective" (Dune and Raby, 2001, p.58; Malpass, 2017, p.41; Torkidsby, 2018).

Participants should create a frictional setting of people and environment, in order to create their design and except the fundamental difference between traditional design thinking and critical design method (Torkidsby, 2018; Cirakoglu, 2018). Finally, they had to discuss and present one outcome. Most of the students liked the 'dark way' of thinking. Few interesting comments from the groups were "I don't believe it's so much of fun, we are at a different level of designing", "this seems to be bit wired, but interesting". By the end of the workshop students had achieved interesting outcomes. "The dark way of thinking evoked both reflections and emotions in relation to the environments being discussed (Torkildsy, 2018, p: 6)

Critical design is influenced by critical social theory and its intention to engage with the audience imagination and intellect to convey to convey massage (Malpass, 2017). It emphasises the role of a designer to make the users understand and raise awareness of their passiveness as citizens. Critical design is an awareness for the designers who assume that design is neutral, clean, and pure, but all designs are ideological, and the design process is informed by the values based on specific world view (Dune \& Raby, 2001). The critical designs developed by the participants in the workshop depart from the assertion of ideological aspect of design. The students design featured elements of cliché' and satire leading the viewer to experience a dilemma; is it serious or not? Real or not? (Dune \& Raby, 2007). All groups had discussion with the group members and the workshop organiser during all stages of design process (fig: 2).

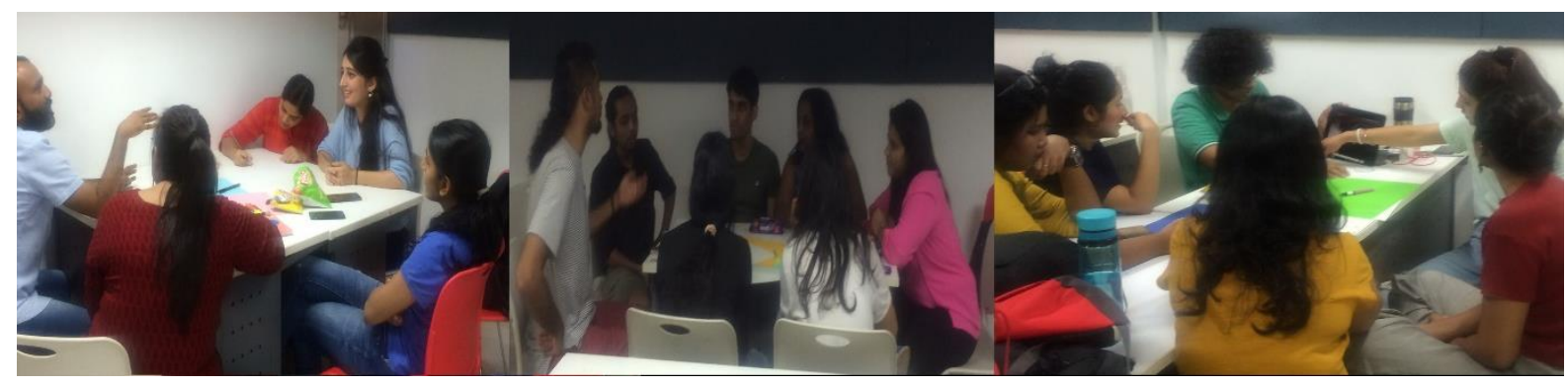

Fig: 2 Initial brainstorming in workshop

"Expert designing is characterised by repeated movement between design detail and design overview and between modes of representation" (McDonnell, 2016, p: 109). The focus on Cross (1984) three phases of prescription, description and observation continues to gain attention for structuring design research was followed by the participants. In order to become critical practitioners, each group should select a scenario and identify a resolved design and reflect critically. They reflect on the identified design and attempt to develop an awareness of learning from them, therefore develop a critical view on the conditions that shaped their experience. To practice critical awareness, initially groups had to create experiences, where the processes were the focus of attention that can be inspected. Here, the participants were open to interpretations and draws attention to some phenomena, and examination of these phenomena. An effective reflection means comparing their own interpretations with perspectives of others (McDonnell, 2016) and it works well with an interdisciplinary group of design students. 
To practice critical design, it does not solve problems but raises questions. It uses designs to explore alternative views of the world and engage audience to a reflective state. Moreover critical design is a method of analysis: how to look at objects in the basis of semiology, that goes beyond the appearances and that questions the neutralisation of power structure. Dune's idea of 'enlightment' is a reference to the Kantian heritage to School of Frankfurt. Accordingly, he emphasises the need to adopt a questioning stance, hence undermining the fallacy of social, cultural, and political determinism (Gentes \& Mollon, 2015).

The participants engaged attentively throughout the workshop and were encouraged to reflect on the given scenarios (Mumbai cinema hall, Mumbai PA canteen and Mumbai metro), the students are remarkably familiar with. They were challenged to reflect and discuss these scenarios under extreme environment prior to stat their designing task. In the context of the scenarios, students explored the idea of box office ticketing in cinema halls, chips disposer in PA canteen and passenger holders in Mumbai metro train.

\section{Reflections and discussions on design development process}

The idea of the workshop is to force the participants from the usual design thinking process of problem solution; instead, encourage them to think out of the box in response to a problem/ design. Stolterman (1994, p: 448) observed "learning should not be a process of conservation where an existing practice is taken for granted as the only answer. Design learning should strive towards a situation where new designers constantly reflect upon and critically examine their design practice". This leads to best designer who can innovate radically.

The scenarios were given to the participant groups by the author, but it was up to the group to decide and evaluate ideas, concepts, and process in a critical manner. They were encouraged to consider the dark side of the design thinking under a fictional scenario for idea generation. However, this way of thinking is used to shed light under familiar experience environments, which support normal state of behaviour, but the participants have to "reject how things are now as being the only possibility and provide a critique of prevailing situation that embody alternative social, cultural, technical, or economic values (Dune \& Raby, 2001).

Group A did brainstorming on 'box office' experience in cinema hall: security check, tickets, waiting lounge, finding their seat, standing for National Anthem, couples making out, trailers, adds, popcorn holders, 3Dglass. In order to get an overall experience of watching a movie that remains as an everlasting memory; they developed the concept of tattooing ticket in their body, where they do not have to buy tickets or be in the que for seating. It gives futuristic experience of watching a fiction movie. The author found Group: A more inclined towards speculative critical design, where they look into future of cinema ticketing, considering futuristic ideas and use of technology to create a personal experience.

Group B looked at the crisp display in Pearl Academy canteen and they found it clumsy, too many packets clustered, cage makes it difficult to select, bad location with no easy access, unorganised with sharp cage edges that hurts their hand, and the cage gives easy nibble for rats to feast on chips. They discussed on redesigning the chip cage with three compartments: blood donation as a good will gesture, Las Vegas theme of bet on your chips or surprise chips, "Jaisa gali waisa chips with a gali" (offensive language) meter that can measure intensity of abuse for stress relief. The design is developed for fun experience and social cause in their college, which encapsulate the concept of working with ideas to 
prove a point by resolving the existing problems with chip cage. Most of the participants liked the concept as they found it engaging, purposeful and interesting experience to grab a pack of chips.

Group C started their discussions based on experience in Mumbai metro train, where short people pull the spring bar at their level making inconvenience for tall ones. They looked at gender equality in train (no women compartment required), moving handles on holding bars, zig zag bars instead of circular one. So, people can bump into each other, trampoline floor, sarcastic poster with writing "hold your bag on your shoulder not on others' feet". Group C started their concept presentation with a skit to engage the audience through the experience of their critical design ideas. The other groups recorded the skit in their phones and counter questioned the participants "are you sure bumping into each other in a crowded train is a pleasant experience?", "why not, an unexpected physical touch that happen accidently can develop into friendship or anger to the other person, whichever way there is an interaction between the passengers that makes the train ride interesting"

During the workshop, the participants mainly discussed what they experience in their daily lives. They developed designs "rejecting the idea of something that is affirmative rather than critical; explanatory rather than affective" (Dune and Raby, 2001

\subsection{Designs developed in the workshop}

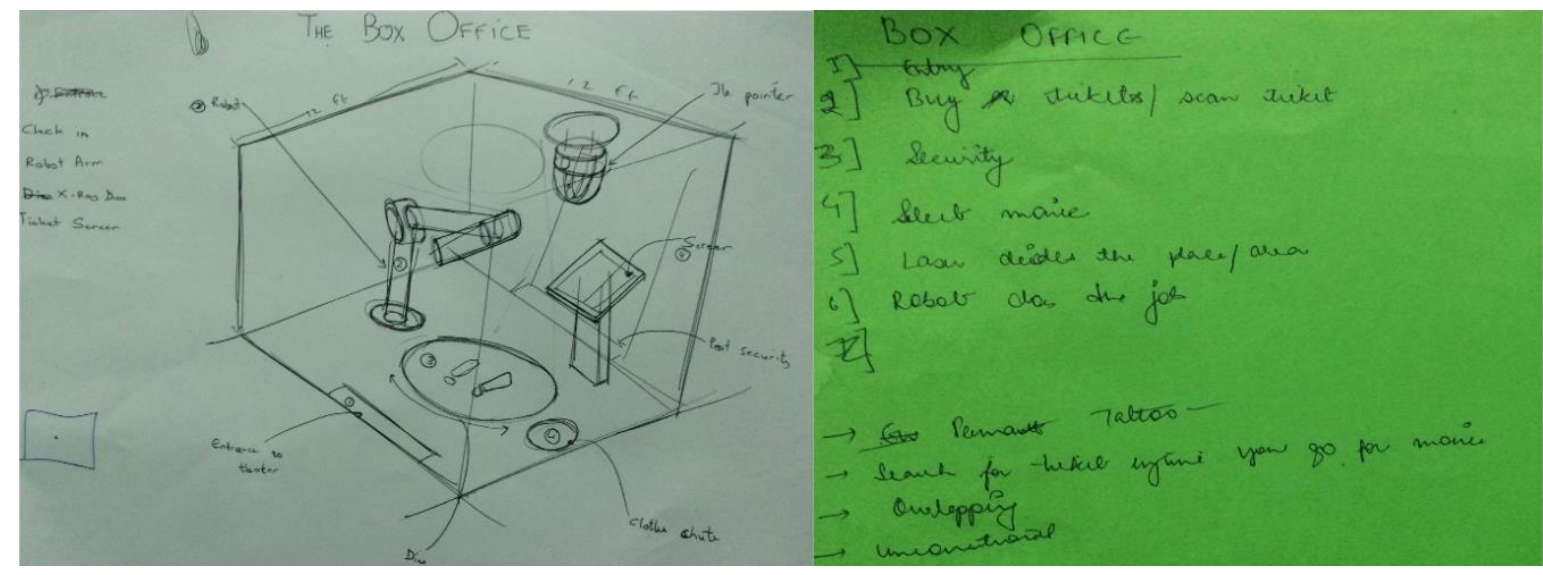

Fig 3: Group A- Box office formula

"To make the box office better in a cinema hall (fig: 3); Instead of people sitting in the counter there is machine to do it. You enter the room and sand on a dais that rotates and select the movie you want to watch. Here we redesign the entire experience of ticketing. Instead of a paper ticket the cinema ticket gets tattooed on your body with permanent ink. So, if you like movies then you can show off the movie list tattooed on your body; the movies you watched first day first show. There is a beam on the top and machine decides where you will get the tattoo. There is a robot on the left side that tattoos the ticket with permanent ink. Basically, the tattoo will remain in your body for ever. The dome camera at the top has a laser beam which will choose which part of the body it should be tattooed. You will be standing in a revolving dais which is automated. The laser beam will point at which area the ticket should be tattooed. If it points on head then you will get bald spot. So, if you want to want to watch your favourite movie then you have to sacrifice a bit" 


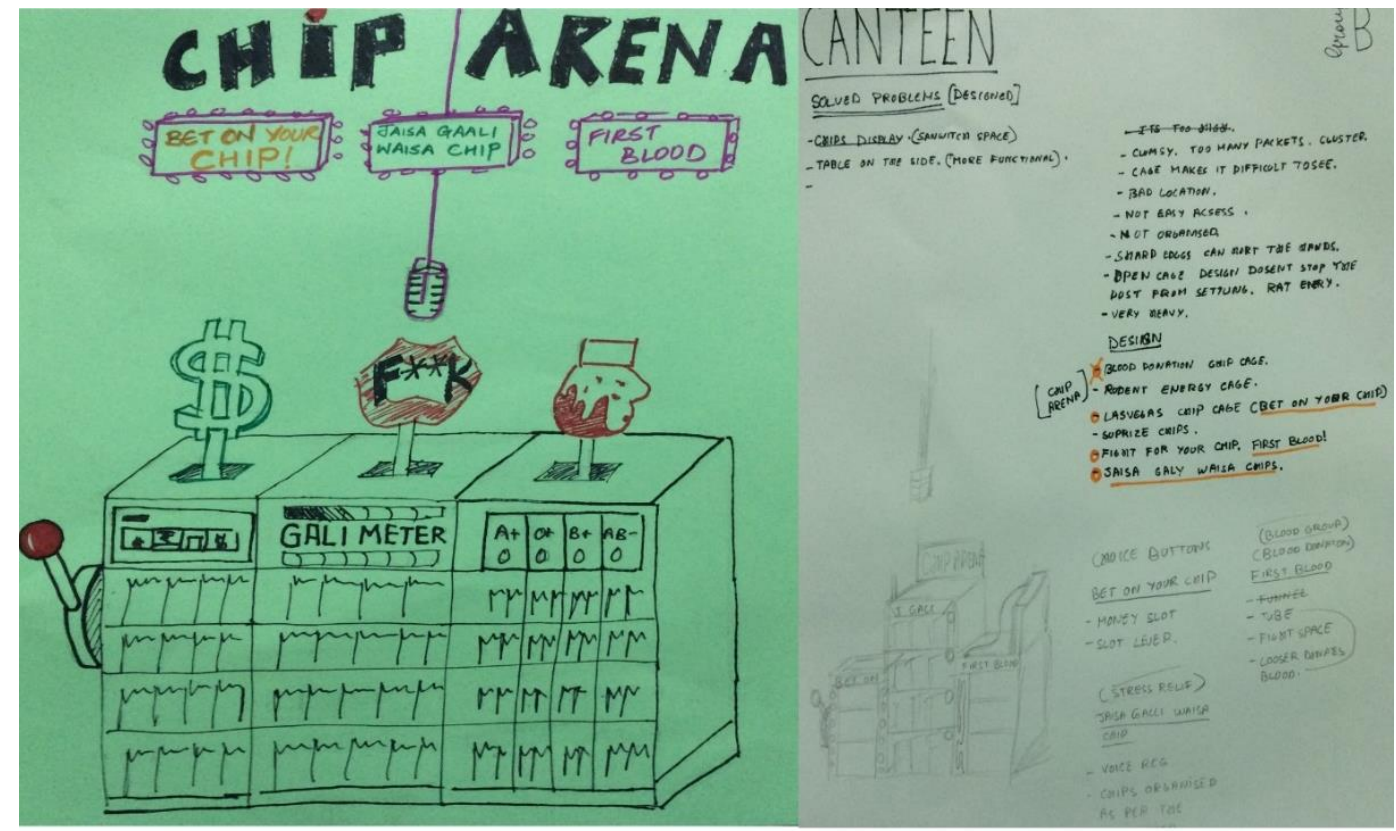

Fig 4: Chips arena in Mumbai Pearl Academy canteen

Group B designed a chip arena with three compartments (fig: 4) "'bet on your chip' were you have to pay the money first and bet for the chips, if you lose you do not get any. Sometimes you get a bonus of two chips or may not get any. There are different combinations and according to it you win the prize. The second one is 'jitna gali utna chips'. It is a gali (offensive language) meter, the higher the gali you get the chip. The choice of your chips depends on your gali. So, if you are frustrated then go and swear to the chip dispenser then you get a pack of chips. So, based on the gali it opens up different levels of chips. The third one is called first blood. You have to donate blood to get the chips, there are different types of blood groups and whoever comes and donates blood gets chips. Each blood group get different types and flavours of chips".

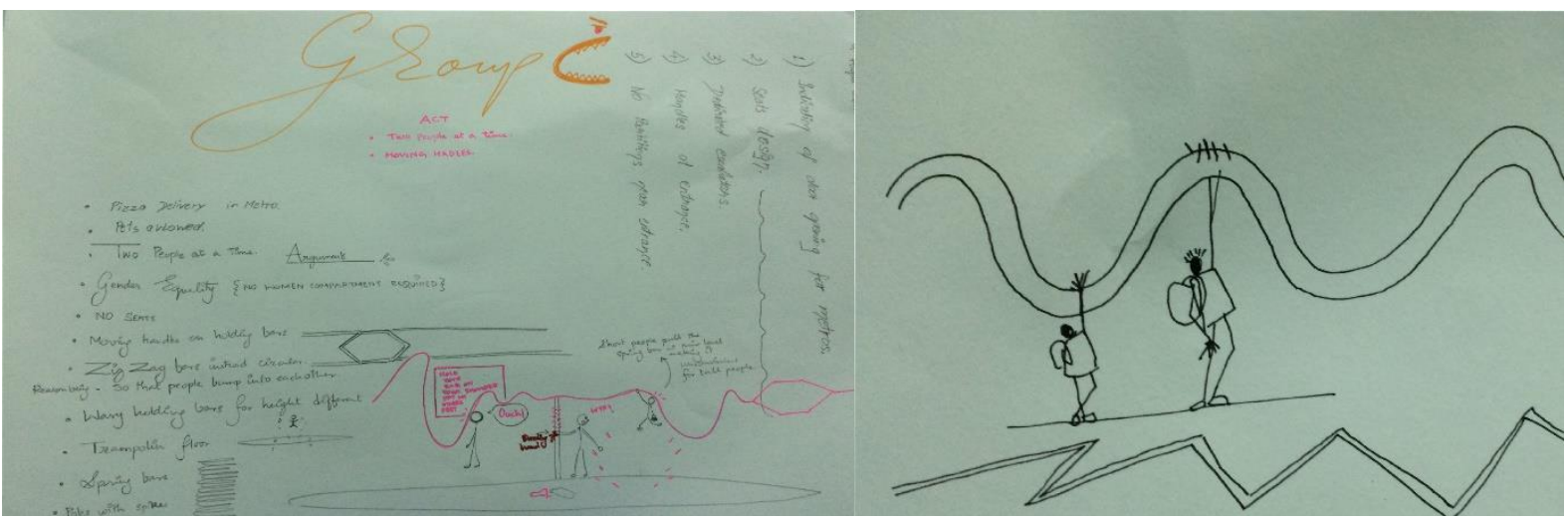

Fig 5: Passenger hangers in Mumbai metro train

Group C (made a skit) on Mumbai metro ride (fig 5 ) "Once you enter the metro train the holding bar is not a straight bar; it is a wavy bar. Why it is wavy bar? is to accommodate both tall and short people. The wavy design will help the short ones to reach the bar. The bars are too close that people 
bump into each other. They might fight or be friends. The metro ride can be good experience making friends or a bad experience with arguments and fights".

The intention of critical designers is to engage with the audiences' imagination and intellect to convey a massage, often under fictive scenarios. Designs are proposed that would not exist under normal consumption models because of social or cultural embargos. The objects designed under critical design suspend the use under uncomfortable place between reality and fiction. These designs arise a question on what to change in our reality, in order to make these products to exist in normal mode of consumption. A debate is encouraged to form a tension between reality and what is inhibited from being real. It works through juvenalian forms of satire where antithesis, obscenity and violence are used to engage the user (Malpass, 2017).

The workshop activities were recorded and analysed using the revised Bloom's taxonomy

- Remember: the brief and the examples of critical design (CD) that was discussed in the beginning of the workshop

- Understand: To summarise what CD is all about

- Apply: through group debates and discussions, design a product with active participation of group members

- Analyse: differentiate between CD examples discussed at the beginning of the workshop; and how each group would develop their own design resolution

- Evaluate: Access whether their design thinking relates with the CD theories

- Create: Compose a skit or develop a design based on CD

\section{Conclusion}

The advantage of critical design in design education is to encourage the students to evaluate their ideas, research, explorations, experimentation, and presentation of designs in a critical manner. Instead of finding problems, they analyse and synthesise problems through asking questions not trying to answer them or find solutions to the existing problem in a design. The intention behind the critical design workshop is to place the students in a situation where they reflect upon and critically examine the designs to meet the needs, wants and desires of the increasingly complex world (Torkildsby, 2018).

The categories in Blooms taxonomy are to understand, apply, analyse, evaluate, and create could be applied in the process of critical design development. According to Jakobsone (2017), there are two important aspects that are underestimated or omitted in traditional design practice and design education, but they are core criteria for critical design practice: it is critically concerned with future and designs potential to shape for the preferable audience or user. Second aspect is to be aware of the ideological constrains that limit the society hider its progress. Critical design as a method could be used to develop personal understanding, promote professional growth of designers, and expand the meaning of design thinking. By setting boundaries and defined structure in design thinking will limit the spectrum of ideas and designs that are preferred by a diverse population who needs personal understanding of their requirements. 


\section{Reference}

Andreson, L, W. \& Krathwohl,D ,R., 2001, A taxonomy for Learning Teaching and accessing: A revision of Bloom's taxonomy for educational objectives, Newyork: Longman. http://eduq.info/xmlui/handle/11515/18824

Bardzell, J. \& Bardzell, S., 2013, What is critical about critical design? In Proc. CHI '13, ACM Press, p: 3297-3306. https://doi.org/10.1145/2470654.2466451

Bhar, A. K. (2019). Design \&amp; implementation of a personal Cash flow program using Microsoft Excel ${ }^{\circledR}$. Global Journal of Business, Economics and Management: Current Issues, 9(1), 29-40. https://doi.org/10.18844/gjbem.v9i1.4032

Cirakoglu, H. (2018). Hand arts and industrial design. New Trends and Issues Proceedings on Humanities and Social Sciences, 5(6), 128-133. https://doi.org/10.18844/prosoc.v5i6.3849

Cross, N., 1984, ed., Developments in Design Methodology. New York: John Wiley \& Sons. https://www.worldcat.org/title/developments-in-design-methodology/oclc/10751646

Dunne, A, \& Raby, F., 2001, Design Noir: The secret life of electronic objects, London: August Media LTD. https://www.amazon.com/Design-Noir-Secret-Electronic-Objects/dp/3764365668

Dunne, A., 1997, 'Hertzian Tales': An Investigation Into The Critical Potential Of Electronic Product as a PostOptimal Object. PhD Dis. London: RCA. http://hdl.handle.net/10068/385346

Eber, P. A., \& Parker, T. S., 2007, Assessing Student Learning: Applying Bloom's Taxonomy. Human Service Education, vol. 27(1). https://tinyurl.com/yimgaypn

Fitsumbirhan, G., Kelkay, A. D., \& Asrat, A. (2020). Data-based decision-making practices in secondary schools of North Gondar, Ethiopia. Global Journal of Guidance and Counseling in Schools: Current Perspectives, 10(1), 36-48. https://doi.org/10.18844/gigc.v10i1.4564

Gentes, A., \& Mollon, M., 2015, Critical Design: a delicate balance between the thrill of the uncanny and the interrogation of the unknown. In D. Bihanic (ed.), Empowering Users through Design: Interdisciplinary Studies and Combined Approaches for Technological Products and Services, Springer. https://doi.org/10.1007/978-3-319-13018-7 5

Haris, S. S., \& Omar, N., 2015, Bloom's Taxonomy Question Categorizatıon Using Rules and N-gram Approach. Journal of Theoretical \& Applied Information Technology, vol: 76(3). https://tinyurl.com/yivdszx7

Jain, P. (2018). Design thinking...inspiring innovation, transforming humanity. Global Journal of Arts Education, 8(2), 68-74. https://doi.org/10.18844/gjae.v8i2.3784

Jakobsone, L., 2017, Critical design as approach to next thinking, The Design Journal, Taylor and Fraincis, vol. 20 (1), p: 4253-4262. https://doi.org/10.1080/14606925.2017.1352923

Kastberg, S. E., 2003, Using Bloom's Taxonomy as a framework for classroom assessment. The Mathematics Teacher, vol: 96(6), p: 402-405. https://doi.org/10.5951/MT.96.6.0402

Krathwohl, D. R., 2002, A revision of Bloom's taxonomy: An overview. Theory into practice, vol. 41(4), p: 212-218. https://doi.org/10.1207/s15430421tip4104 2

Malpass, M., 2017. Critical Design in Context - History, Theory and Practises. London: Bloomsbury. https://www.bloomsbury.com/uk/critical-design-in-context-9781472575180/

McDonnell, J., 2016, Gifts to the future: Design, reasoning, design research and critical design practitioners, Central $\begin{array}{lllll}\text { Saint } \quad \text { Martins, University of } & \text { Arts, }\end{array}$ https://ualresearchonline.arts.ac.uk/id/eprint/9819/1/1-s2.0-S240587261600006X-main.pdf

Özdemir, F. (2020). Management in the Hypermodernity. Global Journal of Sociology: Current Issues, 10(1), 0914. https://doi.org/10.18844/gjs.v10i1.4751 
Ravell, T, \& Voss, G., 2018, This must be the place: Critical design and urban futurity, accessed on July 26, 2019, available at: https://www.researchgate.net/publication/327035198

Robyn, E., 2014, Bloom's taxonomy. Denver, CO: Expert Beacon, Accessed on 30th of July, 2019 available from http://expertbeacon.com/blooms-taxonomy/\#.VZGfGOalUOw

Spence, J., Frohlich, D. \& Andrews, S., 2015, Performance and critical design, accessed on August 5th, 2019, available at: https://www.researchgate.net/publication/300204246

Stolterman, E., 1994, Guidelines or Aesthetics: Design Learning Strategies, Science direct, vol15 (4), p: 448-458. https://doi.org/10.1016/0142-694X(94)90007-8

Torkildsby, A, B., 2018. , Critical Design in Universal Design Settings: Pedagogy Turned Upside down", journal for design and technology education, vol 23 (2), p:1-18. https://ojs.lboro.ac.uk/DATE/article/view/2432

Verganti, R., 2008, Design, meanings and Radical innovation: A meta model and a research agenda. Journal of product innovation management. https://doi.org/10.1111/i.1540-5885.2008.00313.x 